\title{
Bimbingan Teknis Renovasi Pembangunan Musholla Nurul Hidayah Dan Tpq Az-Zahiroh Dusun Dermo Desa Mulyoagung Kecamatan Dau Kabupaten Malang
}

\author{
Qomariah $^{1}$, Rinto Sasongko ${ }^{2}$, Sugiarti ${ }^{3}$, Sugeng Riyanto ${ }^{4}$, Sunarto Suryanto ${ }^{5}$ \\ 1,2,3,4,5 Jurusan Teknik Sipil, Politeknik Negeri Malang \\ e-mail: ${ }^{1}$ qomariah@polinema.ac.id, ${ }^{2}$ rinto.sasongko@polinema.ac.id, ${ }^{3}$ sugiarti@polinema.ac.id, \\ ${ }^{4}$ sugeng.riyanto@polinema.ac.id, ${ }^{5}$ sunarto.suryanto@polinema.ac.id
}

\begin{abstract}
Abstrak
Kegiatan pengabdian kepada masyarakat ini bertujuan untuk memberikan bimbingan dan pelatihan tentang pentingnya pengembangan kepribadian kepada masyarakat khususnya kaum wanita yang terorganisasi dalam kegiatan sosial kemasyarakatan khususnya kelompok PKK. Sesuai dengan tujuan dari organisasi ini adalah untuk memberikan pendidikan kesejahteraan keluarga dan masyarakat secara intensif agar para ibu-ibu sebagai pendidik paling pertama di keluarga dan anakanaknya dirumah serta lingkungan masyarakat pada umumnya

Metode yang digunakan dalam kegiatan pengabdian ini adalah ceramah dan tanya jawab, yaitu penyampaian materi tentang karakter kepribadian dan cara mengembangkannya. Selain ceramah juga dilakukan diskusi dan Tanya Jawab untuk memberikan kesempatan kepada peserta dalam memahami lebih lanjut tentang materi yang disampaikan. Hasil dari kegiatan ini adalah bahwa para peserta memperoleh wawasan dan pemahaman (kognisi) tentang pentingnya etika dan cara mengembangkan diri khususnya dalam menghadapi perkembangan kehidupan di era globa ini, sehingga dapat menerapkan kepribadian yang efektif dalam kehidupan sehari-hari dan mudah beradaptasi dengan perkembangan teknologi.
\end{abstract}

Kata kunci-Pelatihan, Pengembangan, Kepribadian

\section{PENDAHULUAN}

$\mathrm{I}^{\mathrm{n}}$ ndonesia merupakan negara yang penduduknya dominasi agama islam, setiap muslim melakukan kegiatan ibadahnya dirumah Allah seperti masjid, musholla atau Surau. Bangunan rumah Allah ini selalu dijadikan tempat beraktifitas seperti sholat lima waktu, pengajian, tempat anakanak belajar Al Qur'an serta kegiatan keagam dari bapak Senan dengan luas tanah lainnya. Salah satunya adalah Musholla Nurul Hidayah yang berada di jalan Raya Dermo, Desa Mulyoagung Kecamatan Dau Kabupaten Malang.

Musholla Nurul Hidayah ini berdiri tahun 1995 pemberian waqof tanah dari bapak Senan seluas $150 \mathrm{M}^{2}$. Setelah 20 tahun lebih lamanya Musholla Nurul Hidayah berdiri dan tetap aktif melaksanaakan aktifitas keagamaan. Dengan bertambahnya kegiatan keagamaan di
Musholla Nurul Hidayah seperti pengajian, taman pendidikan Alqur'an, terbang Jidor anak-anak menjadikan musholla Nurul Hidayah menjadi ramai. Kondisi musholla Nurul Hidayah ini dijadikan juga untuk TPQ (Taman Pendidikan AlQur'an) Az-Zahiroh luasnya sangat kecil, karena untuk kegiatan sholat, untuk kegiatan keagamaan dan jumlah anak-anaknya bertambah. Ketika memasuki bulan Romodhon, jamaah musholla Nurul Hidayah tidak mendapatkan tempat untuk beribadah melaksanakan sholat taraweh berjamaah, dikarenakan luasan musholla yang terbatas. Pada pertengahan tahun 2015, bapak Lawi sekeluarga memberikan waqaf tanah seluas $84 \mathrm{~m}^{2}$ untuk dijadikan penambahan dan pelebaran Musholla Nurul Hidayah.

Sehubungan dengan kondisi Musholla Nurul Hidayah yang terletak di Dusun Dermo Desa Mulyoagung, Kecamatan Dau Kabupaten Malang yang baru saja mendapatkan tambahan 
tanah wakaf, maka ada perencanaan untuk membangun dan memperluas bangunan Musholla Nurul Hidayah dan juga ditambah dengan pengembangan TPQ Az-Zahiroh dan halaman parkir musholla sebagai sarana ibadah dan pengembangan untuk tempat pembelajaran agama anak-anak yang layak dan nyaman. Untuk merealisasikan rencana pengembangan tersebut, maka perlu dukungan dari semua pihak baik masyarakat yang tinggal didaerah Dermo, masyarakat sekitar, dari donatur yang dapat mendonasikan rezekinya dan dari pihak lain yang tidak mengikat.

Selain itu, masyarakat didaerah Dermo ini mayoritas beragama islam sehingga termasuk perumahan yang padat penduduk. rumah tinggal adalah salah satu hal yang sangat penting bagi kehidupan manusia, karena tanpa tempat tinggal manusia tidak akan dapat hidup dengan nyaman dan aman. Dalam menjalani kehidupan sehari-hari, manusia tidak pernah lepas dari hal-hal yang berhubungan dengan tempat dimana dia tinggal. Selain kebutuhan hidup manusia yang berkaitan langsung dengan jasmaniah tersebut, maka kebutuhan rohaniah juga merupakan hal yang tidak kalah penting dalam memotivasi aktifitas hidupnya.. kegiatan keagamaan dan peringatan hari besar Islam, khususnya.

Berdasarkan uraian tersebut di atas, maka Politeknik Negeri Malang sebagai institusi pendidikan yang wajib melaksanakan tugas pokok Tri Dharma Perguruan Tinggi perlu berpartisipasi aktif dengan menyumbangkan pemikiran melalui unsur Pengabdian Kepada Masyarakat (PKM). Musholla Nurul Hidayah ini yang akan dibangun/direnovasi ini dengan adanya tambahan lahan seluas $84 \mathrm{~m} 2$ diareal dusun Dermo, untuk merealisasikan bentuk PKM te1rsebut, team dari jurusan Teknik Sipil

Politeknik Negeri Malang berencana memberikan bimbingan teknik pembangunan

Musholla Nurul Hidayah, dengan harapan dapat dipertimbangkan dan bermanfaat bagi warga dusun Dermo Rt 02/Rw02 Desa Mulyoagung, Kecamatan Dau Kabupaten Malang dan sekitarnya.

\section{TATA RUANG DAN SPESIFIKASI MUSHOLLA}

Dalam Rukun Islam yang kedua, shalat lima waktu merupakan hal yang wajib dilaksanakan oleh setiap Muslim. Sebelummelaksanakan shalat, umat Islam diwajibkan untuk berwudhu sebagai cara untuk menyucikan diri sebelum menghadap Allah SWTdan sebagai syarat sahnya shalat. Dengan demikian, dapat dikatakan kesempurnaan dan sahnya shalat sangat bergantung darikesempurnaan wudhu. Al Quran dan Hadits sebagai 2 sumber hukum Islam yang utama telah memberikan petunjuk mengenai tatacara wudhu yang baik, dan disempurnakan dengan ijtihad para ulama. Wudhu yang dilaksanakan dengan baik adalah prasyarat diterimanya shalat. Rasulullah SAW bersabda: "Shalat salah seorang diantara kalian tidak akan diterima apabila ia berhadas hinggaia berwudhu " (H.R. Abu Hurairah). Dari aspek tata ruang, masih seringnya ditemui tempat wudhu dengan sirkulasi yang kurang baik, diantaranya adalah aksesibilitastempat wudhu yang harus dicapai dengan memutar tempat shalat, tempat wudhu dan tempat shalat tidak berada dalam satu batassuci, serta letak toilet yang berada di dekat tempat wudhu sehingga dikhawatirkan air cipratan toilet tercampur ke dalam tempatwudhu dan menyebabkan najis. Permasalahan tata ruang dan morfologitempat wudhu tersebut masih dijumpai di berbagai tempatwudhu di masjid maupun mushola dan kondisi tersebut masih kurang disadari oleh para pengguna masjid atau mushola. Hinggasekarang belum terdapat rekomendasi bagaimana penggunaan air yang efisien dalam kegiatan wudhu, baik ditinjau dari komponen jenis kran maupun pemanfaatan kembali limbah air wudhu. Permasalahan lain yang menjadi ganjalan bagi pelaku wudhu adalah fasilitas tempat wudhu yang cukup penting bagi pengguna, diantaranya adalah tempat untuk meletakkan barang-barang yang masih melekat pada tubuh ketika memasuki area wudhu, seperti jam tangan, kacamata, pecis/kopiah, sarung, jilbab, asesoris, dansebagainya. Selain itu, permukaan lantai yang licin menjadi permasalahan penting, karena dapat membahayakan pengguna. 


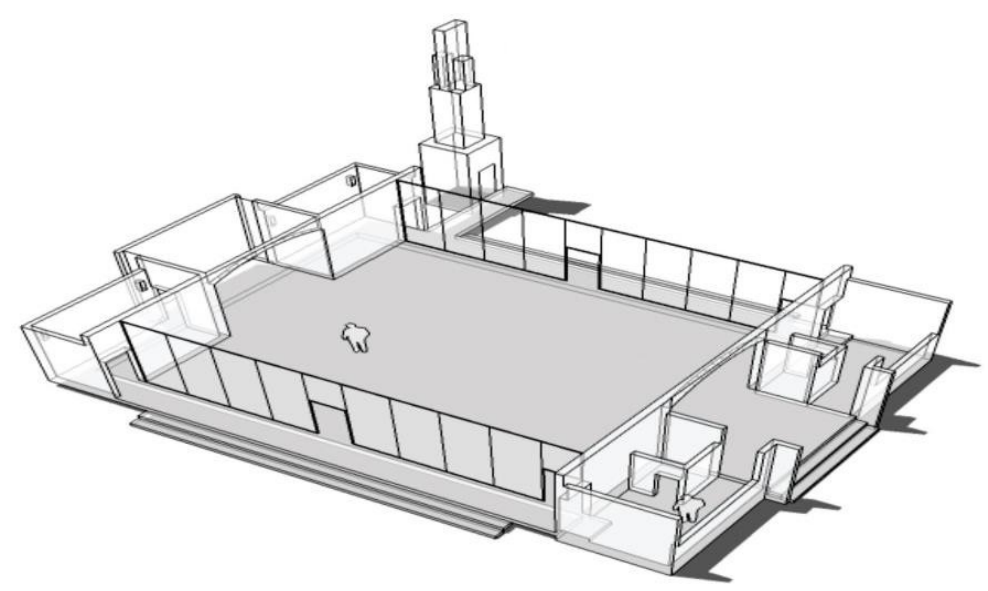

Gambar 1. Denah pintu masuk dan keluar Musholla

\section{PEMBANGUNAN TAMAN PENDIDIKAN AL-QUR'AN (TPQ)}

Masyarakat di wilayah dusun Dermo RT 02 RW 02 desa Mulyoagung dan sekitarnya mayoritas beragama Islam. Dalam perkembangannya, jumlah

penghuninyapun meningkat, baik dalam wilayah maupun di sekitarnya, sehingga sarana dan prasarana ibadah umat muslim tempat belajar agama bagi anak-anak perlu disesuaikan dalam memfasilitasi kegiatan kerohanian dan keagamaan. Ketersediaan lahan di wilayah tersebut memungkinkan untuk dibangun tempat taman pendidikan AlQur'an dan penggeseran musholla yang lama. Diawali dengan bangunan pe munduran lokasi musholla yang lama dan akan dikembangkan untuk menjadi bangunan /ruang tambahan untuk pasilitas TPQ AZ-Zahiroh yang akan menjadi Musholla Nurul Hidayah \& TPQ AZ-Zahiroh.

Perlunya meningkatkan penataan dan revitalisasi kawasan dalam mewujutkan lingkungan musholla yang kondusif, termasuk tersedianya sarana dan prasarana peribadatan. Hal ini dimaksudkan demi keberlangsungan dan keberlanjutan lingkungan/kawasan dalam rangka menciptakan lingkungan yang seimbang dan terintegrasi dalam pengembangan wilayah khususnya wilayah $\mathrm{Rt}$ 02/Rw 02 Desa Mulyoagung tersebut.

\section{RENCANA PERGESERAN MUSHOLLA}

Musholla Nurul Hidayah sekarang, lokasi sebenarnya sangat dekat dengan jalan, dengan adanya waqaf tanah sebesar $84 \mathrm{~m} 2$, maka posisi musholla dapat digeser mundur lebih menjauhi jalan, sehingga dengan pergeseran dari musholla ini, maka areal musholla tadi yang sudah bergeser, dapat dimanfaatkan untuk membangun tempat taman pendidikan Al-Qur'an (TPQ). Luasnya areal untuk bangunan TPQ dan halaman parkir tersedia ukuran 7,1 m x 12.1 meter. Dapat dilihat pada denah lama (terlampir). Rencana perubahan bangunan yang akan dilakukan adalah menggeser lokasi musholla Nurul Hidayah yang dapat dilihat pada lampiran Denah yang baru. Luasan musholla diperluas dari ukuran yang lama, sehingga dengan pelebaran luasan dapat juga difungsikan sebagai taman pendididkan Al Qur'an.

Pembangunan musholla yang tadinya hanya satu lantai, dengan penegembangan luasan dijadikan dua (2) lantai, dan ini sudah berjalan serta masih dalam pelaksanaan.

\section{TAHAP PEMBANGUNAN KUBAH MUSHOLLA}

Bagian dari masjid yang sangat penting dan perhatian khusus selalu kubah. Saat ini, kreasi kubah yang paling serbaguna yang unik dan menarik sebagai kubah itu sendiri adalah ikon dari sebuah masjid. Berbicara tentang kubah masjid, tentu saja di setiap masjid yang sering ditemui, melihat kubah yang berbeda. Sementara dalam pembuatan kubah juga tidak mudah. Untuk kubah yang indah dan menawan, harus melalui proses yang panjang dan ketat. Oleh karena itu, bagi mereka yang ingin membuat kubah masjid, harus belajar terlebih dahulu apa yang 
harus dilakukan dalam produksi ini. Nah, di sini kita harus bertanya adalah bukan bagaimana melakukannya dan bagaimana membuat kubah masjid di tahap awal ini. Jika demikian, jangan khawatir karena jawaban rasa ingin tahu Anda di sini. Adapun rincian, lihat silahkan langsung untuk menyimak ulasan di bawah ini.

Langkah pertama yang perlu Anda lakukan pasti untuk menentukan desain. Dalam hal ini, desain sangat penting untuk diperhatikan. Pastikan untuk membuat desain yang dihuni oleh arsitektur masjid dan ukuran. Sementara itu, dalam pembuatan desain sendiri, Anda dapat menggunakan komputer dengan spesifikasi tertentu. Keuntungan dari desain kubah menggunakan komputer Anda sendiri, Anda dapat mempertimbangkan optimalisasi bahan. Juga, jika Anda bingung tentang

bagaimana bentuk model ini, Anda dapat menemukan beberapa contoh desain pertama dari kubah masjid Internet.

\subsection{Material Untuk menentukan kubah beton}

Setelah mendapatkan desain untuk kubah untuk melakukan langkah kedua dari cara untuk membuat kubah masjid adalah untuk menentukan bahan apa yang akan digunakan. Bahan untuk kubah itu sendiri, ada berbagai jenis. Setiap subjek memiliki kelebihan dan kekurangan. Oleh karena itu, pilihan peralatan, Anda harus merencanakan terlebih dahulu apa yang akan menjadi prioritas. Sementara beberapa bahan yang banyak digunakan sebagai bagian pracetak beton masjid atau kubah beton yang biasanya disebut GRC material, enamel dan galvalum, serta perangkat keras dan Stailess.

\subsection{Bahan beton}

Kubah terbuat dari bahan beton kubah klasik karena lama nenek moyang kita membuat kubah bahan bumi atau beton. Kubah kelebihan material beton dalam hal daya tahan. Memang, kubah material beton sangat kuat, jelas dari banyak masjid sejarah yang kubah beton yang masih dapat dilihat sampai hari ini, meskipun itu sudah ratusan atau bahkan ribuan tahun. Seiring waktu, sekarang muncul nama bahan beton serat atau lebih dikenal dengan GRC (beton, fiber glass). GRC adalah pengganti perangkat keras atau substitusi kubah beton bertulang untuk terlihat lebih indah dan cantik.

Keuntungan menggunakan GRC adalah massa dari kubah lebih ringan dari bagian bawah GRC yang merupakan jenis serat yang memiliki salah satu dari serat tulangan beton dalam bentuk fiberglasss. Selain kubah akan lebih kuat, berkelanjutan, proses ini lebih mudah.

Mulai dari tahap pengembangan

Akhirnya, ketika memilih desain dan bahan selesai, Anda dapat terus membangun kubah. Inilah hal pertama yang harus dilakukan adalah untuk menciptakan kerangka kerja untuk kubah. Secara umum, untuk penyusunan kerangka kubah menggunakan tabung vakum, dan sebagainya.

Setelah order produksi selesai, itu akan menginstal panel kubah. Dalam hal ini, proses akan menjadi bagian atas pelat pemotongan kemudian dilipat dengan cara mesin tertentu. Setelah proses ini selesai, selanjutnya adalah pemasangan langit- langit berkubah dan pewarna. pewarnaan ini mungkin dua metode untuk memilih metode perendaman dan metode semprot. Nah, setelah pewarnaan selesai, konstruksi selesai dengan kedatangan untuk memperindah kubah yang Anda inginkan dalam dan di luar.

Ini adalah beberapa cara bikin kubah masjid dari beton dan bagaimana membuat kubah masjid pada tahap awal. Dengan beberapa prosedur, Anda bisa mendapatkan sebuah kubah yang indah dari masjid dan sempurna. Sementara itu, untuk mempercantik kubah, Anda dapat memberikan baik di dalam dan di luar ornamen yang dipilih.

Ketika membuat sebuah masjid dengan memiliki ukuran yang cukup besar atau penampilan mewah lebih menarik, memilih warna cat elegan adalah salah satu yang kita harus memperhatikan nilai riil dan benar.

Yang pertama dalam pemilihan warna cat melihat ke depan atau melihat juga di bagian belakang. Dengan warna cat rumah mewah hanya merancang penelitian masa depan. Nah, ada banyak jenis sampel warna cat jika Anda menarik bagian depan dengan warna itu. Nah dalam laporan ini juga sangat baik sekali dalam

diskusi sampel warna cat masjid terbaru dan minimalis, contoh mengecat 
masjid, cat dinding masjid, minimalis warna cat masjid melihat ke depan, cat eksterior, cat interior, model cat minimalis dan sebagainya.

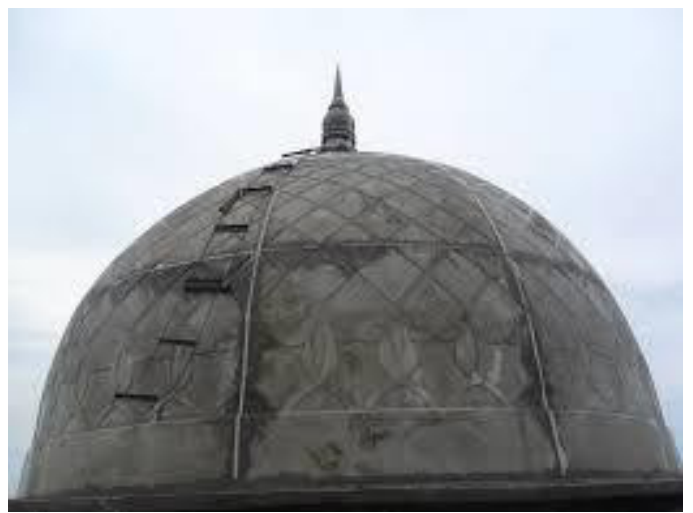

Gambar 2. Kubah beton Musholla

6. PELAKSANAAN PEMBANGUNAN MUSHOLLA

Ada beberapa prosedur yang harus dilakukan dalam pemasangan/pembuatan pondasi batu kali, agar diperoleh hasil yang baik, antara lain:

1. Ukur tanah yang akan di pasang pondasi, kemudian pasanglah bowplang untuk menggetahui ketinggian muka tanah setelah itu pasang benang agar pondasi bisa tegak dan lurus.

2. Gali tanah yang akan di buat pondasi dengan kedalaman sekitar setengah meter karena pondasi tersebut dibuat untuk pagar tembok yang mempunyai ketinggian 3 meter saja.

3. Landasan tanah tersebut diberi anstamping dengan ketinggian sekitar $20 \mathrm{~cm}$, dengan posisi batu tegak.

4. Pasir dan semen di campur dengan menggunakan perbandingan 1:5 kemudian campur dengan air secukupnya sebagai pengikat dengan menggunakan alat pengaduk molen.

5. Susun batu kali tersebut diatas anstamping setinggi $80 \mathrm{~cm}$.

6. Setelah semuanya tercampur dengan baik tuangkan campuran tersebut ke dalam batu kali yang tersusun tadi sambil di padatkan dengan menggunakan tongkat besi agar campuran tersebut memadati lobanglobang yang berada di podasi batu kali tersebut.
7. Setelah itu tunggu pasangan batu kali tersebut hingga mengeras dan siap untuk di beri beban di atasnya.

Kelemahan dari bahan bangunan yang di gunakan untuk pemasangan pondasi batu kali menurut teori dan pendapat saya tidak ada kelemahan di dalam penggunaan bahan bangunan dikarenakan semua bahan bangunan yang di gunakan di proyek semuanya sama dengan teori yang ada di dalam perkuliahan. Pengecekan yang saya lakukan secara fisik yaitu dengan cara sedikit menggoyangngoyangkan pondasi untuk mengetahui kokoh atau tidaknya pasangan pondasi batu kali tersebut.

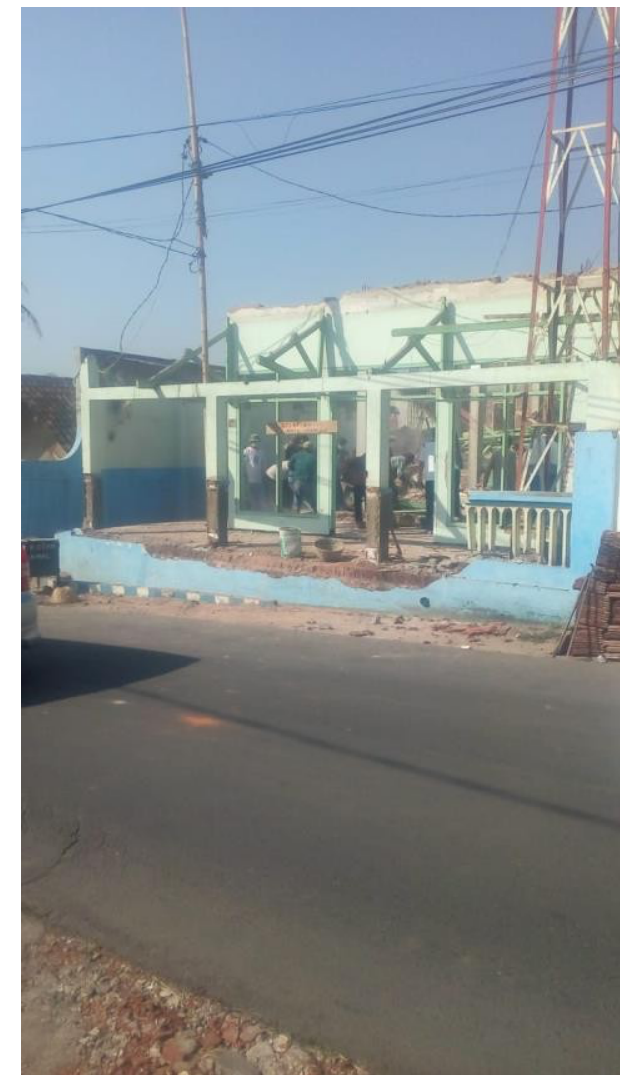

Gambar 3. Pembongkaran Musholla Nurul Hidayah lama

Pondasi bangunan memiliki peran yang sangat penting pada saat hendak membangun sebuah bangunan. Bentuk pondasi biasanya disesuaikan dengan berat bangunan dan kondisi tanah yang ada di sekitar bangunan. Sedangkan kedalaman pondasi ditentukan berdasarkan letak tanah padat yang akan menopang pondasi.

Secara garis besar, pondasi bangunan dibagi menjadi dua yaitu pondasi dalam dan pondasi dangkal. Pondasi dangkal digunakan untuk pondasi yang memiliki kedalaman $0,8-$ 
1 meter. Pondasi dangkal dibagi menjadi 5 jenis.

Kesimpulan yang dapat diambil dari hasil pengamatan yaitu semua bahan banguanan yang di gunakan untuk memasang pondasi batu kali semuanya sama dengan teori, tetapi yang membedakan yaitu perbandingan campuran yang digunakan tidak sama dengan teori. Dengan perbedaan campuran yang di gunakan untuk pasangan tersebut secara kekuatan fisik tidak jauh beda dengan pasangan pondasi batu kali yang menggunakan campuran secara teori.

\subsection{Pemasangan Dinding}

Sebuah rumah tanpa kehadiran mushola rasanya kurang lengkap bagi keluarga muslim. Meski salat sebenarnya bisa dilakukan di kamar, adanya mushola dapat menambah ketentraman dalam beribadah. Selain terhindar dari gangguan, suasana damai dalam mushola pun bisa membuat ibadah jadi lebih khusyuk.

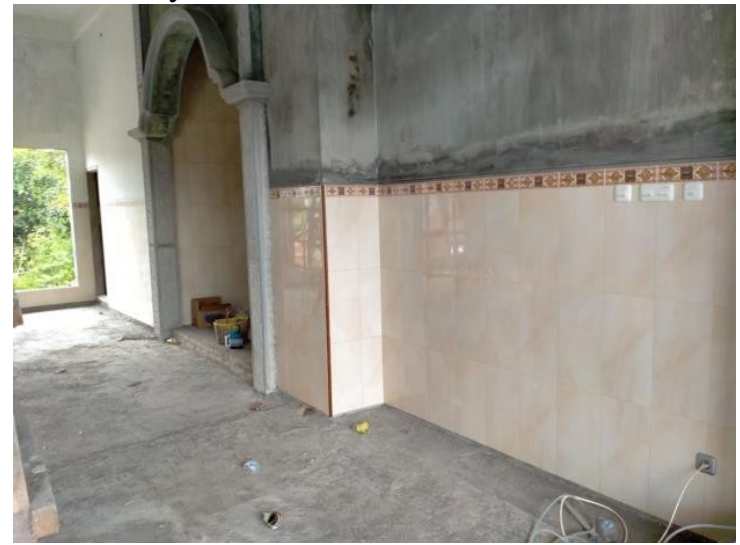

Gambar 4. Tampak diding dalam Musholla Nurul Hidayah

Tampilan mushola tentu saja tak perlu mewah dan berukuran besar, dekorasi dan penempatan yang tepat akan memberikan kesan dan ketenangan tersendiri dalam beribadah sehingga suasana yang khusyuk bisa lebih mudah diperoleh. Bagi kamu keluarga muslim yang sedang mencari ide untuk dekorasi mushola di rumahmu, yuk kita simak terlebih dahulu 10 dekorasi mushola supaya ibadah lebih khusyuk berikut ini Mencontoh dekorasi dinding masjid untuk mushola di rumah tidak ada salahnya. Kamu bisa menempatkan kaligrafi surat Al-Fatihah yang terbuat dari keramik di sekeliling dinding mushola. Penambahan beberapa kaligrafi berbingkai bertuliskan kaligrafi tulisan Arab yang digantung pada tembok jangan sampai berlebihan. Tembok putih polos dengan hiasan dinding dekoratif seperti ini saja sudah mampu memberikan ketenangan dalam beribadah. Adanya tempat wudu di samping mushola dapat membuat keluarga tak ragu berlamalama di mushola untuk beribadah, sekiranya harus berkali-kali berwudu. Tak perlu berpikir untuk menambahkan banyak keran, taruh sebuah ember besar yang bisa menampung air pun sudah cukup. Tentu saja yang perlu diperhatikan adalah aliran air bekas wudu dan sekat agar air tidak membasahi mushola.
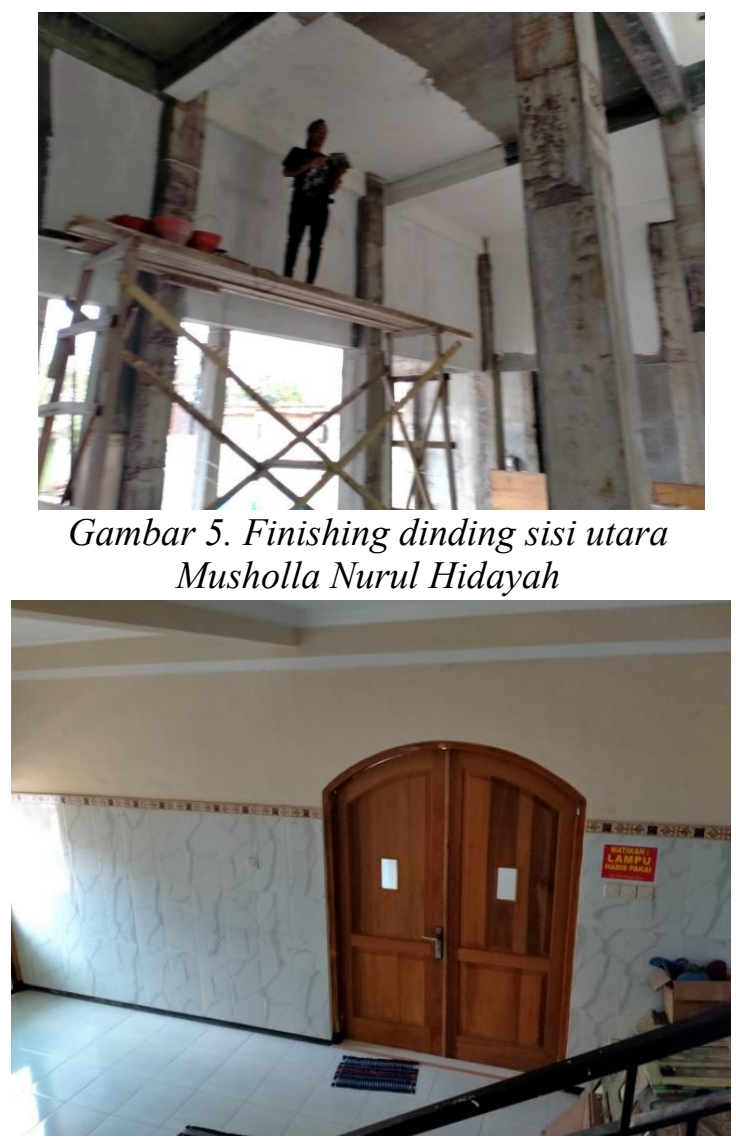

Gambar 6. Finishing dinding dalam Musholla Nurul Hidayah

\subsection{Pemasangan Kolom Musholla}

Ada beberapa jenis kolom yang digunakan di berbagai bagian struktur bangunan. Kolom adalah bagian struktural vertikal yang menopang beban terutama dalam struktur bangunan. Fungsi kolom adalah memindahkan beban dari langit-langit, pelat lantai, atap, atau dari balok ke pondasi 
bangunan. Umumnya, kolom juga menopang momen lentur sekitar satu atau kedua sumbu penampang. Dalam artikel ini aa dijelaskan berbagai jenis kolom yang digunakan dalam konstruksi bangunan. Kolom diklasifikasikan berdasarkan beberapa kondisi yang berdasarka pada berbagai hal meliputi: Berdasarkan Jenis Penguatan, Berdasarkan Jenis Pemuatan, Berdasarkan pada Slenderness Ratio, Berdasarkan Bentuk, Berdasarkan pada Bahan Konstruksi. Jenis kolom berdasarkan penguatan, meliputi :

\section{KESIMPULAN}

Hasil perhitungan dan renovasi Musholla Nurul Hidayah dan TPQ AZZahiroh RT 02 RW 02 dusun Dermo desa Mulyoagung, Kecamatan Dau Kabupaten Malang dapat disimpulkan sebagai berikut :

Musholla Nurul Hidayah dan TPQ AZ-Zahiroh RT 02 RW 02 dusun Dermo desa Mulyoagung, Kecamatan Dau Kabupaten Malang sebagai pusat keagamaan dan kemasyarakatan sebaiknya dapat memenuhi kebutuhan masyarakat muslim

terutama dalam kenyamanan, kekhusukan beribadah dan sosial masyarakat, termasuk sarana kelengkapan diantaranya tempat bersuci yaitu ruang wudhu yang bersih, lancar dan nyaman. Dengan dibuatnya Gambar Rencana dan Rencana Anggaran Biaya (RAB) dan perhitungan Analisa Harga Satuan (AHS) pekerjaan, maka pelaksanaan pembangunan dapat berjalan sesuai dengan program pendanaan yang dibuat ini. Dengan setelah dapat dibangunnya pembangunan dan renovasi Musholla Nurul Hidayah dan TPQ AZZahiroh RT 02 RW 02 dusun Dermo desa Mulyoagung, Kecamatan Dau Kabupaten Malang, nanti kiranya dapat mengakomodasi dan meningkatkan kegiatan beribadah, kegiatan keagamaan, dan terciptanya ukhuwah Islamiyah dalam masyarakat dilingkungan Musholla Nurul Hidayah dan TPQ AZZahiroh RT 02 RW 02 dusun Dermo desa Mulyoagung, Kecamatan Dau Kabupaten Malang.

\section{SARAN}

Saran dapat diberikan sebagai berikut:
Perlu pengawasan dengan baik pada saat pelaksanaan sambungan antar elemen baja karena sambungan beton pracetak tentu tidak semonolit seperti pada sambungan dengan cor setempat agar nantinya pada saat memikul beban tidak terjadi gaya-gaya tambahan yang tidak diinginkan pada daerah sambungan akibat dari kurang sempurnanya pengerjaan sambungan.Untuk produksi dilokasiharus memperhitungkan luas lahan agar tidak menggangu saat pelaksanaan konstruksi. Perlu dilakukan analisis terhadap aspek biaya produksi, waktu produksi, dan K3 agar pemilihan metode pelaksanaan produksi lebih kompleks.

DAFTAR PUSTAKA 